\title{
El impacto de la colonización dirigida en la frontera sur. Análisis de la ribera del río Hondo en Quintana Roo, 1970-1980
}

\author{
Martha Patricia Mendoza Ramírez \\ CIESAS SURESTE-SUBSEDE CHETUMAL
}

\begin{abstract}
Análisis de los resultados de la política de colonización dirigida en el estado de Quintana Roo, como parte de los programas de desarrollo regional emprendidos por el gobierno federal. Se estudia particularmente la región del río Hondo y el impulso dado a su colonización a partir del gobierno de Luis Echeverría. Si bien se consiguió poblar esta región, los resultados económicos, sociales y naturales fueron negativos.
\end{abstract}

\section{INTRODUCCIÓN}

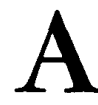

partir del sexenio del presidente Adolfo López Mateos el sureste del país cobró especial importancia dentro de las políticas públicas de desarrollo regional. Por el enorme potencial del trópico (su riqueza forestal, su gran cantidad de ríos y lagunas, así como sus enormes superficies sin poblar) se pensó que podría convertirse en una región altamente desarrollada, cuyo crecimiento impactaría las zonas aledañas. Se diseñaron notables programas de electrificación, de construcción de caminos y presas, así como vastos planes de desarrollo agricola-ganadero, como el Plan Limón (más tarde denominado Plan Chontalpa) y el Balancán-Tenosique, ambos para el estado de Tabasco, y el de Uxpanapa, para el estado de Veracruz. ${ }^{1}$

Los programas de colonización dirigida formaron parte de estas políticas y durante el periodo de López Mateos se dictaron medidas tendientes a su realización; entre éstas destacaron la

\footnotetext{
${ }^{1}$ Tales experiencias han sido analizadas en diferentes estudios. Véase: Tudela, Modernización, 1988, y Casco, Planes, 1980.
} 
formulación del Plan Nacional de Colonización por parte del entonces Departamento de Asuntos Agrarios y Colonización (DAAYC), que tenía como uno de sus principales objetivos dotar de tierra en propiedad al "excedente humano" que carecía de ella. ${ }^{2}$ Otra medida trascendente fue la promulgación de una ley que establecía que los terrenos nacionales se destinarían a la colonización ejidal bajo la forma de nuevos centros de población ejidal, o bien a la dotación y ampliación de los poblados ya establecidos, quedando prohibida la colonización privada. ${ }^{3}$

Se suponía que los programas de colonización dirigida resolverían dos grandes problemas. Por un lado, parecían ser la más aconsejable opción para dotar de tierra a miles de campesinos con derechos a salvo, sobre todo de las zonas del norte y del centro del país; por otro, contribuirían al desarrollo de los estados del sureste, ya que se acompañarían con fuertes in. versiones del gobierno federal,tanto en el ámbito productivo como en infraestructura.

A principios de los años sesenta, fuentes oficiales estimaban que alrededor de 1300000 has serian destinadas a este proceso. Las tierras aludidas se ubicaban principalmente en los esta-

2 "Un millón", Excélsior, 5 de mayo de 1960.

3 Con esta legislación, dictada en 1962, se creó una variante nueva en las formas de tenencia de la tierra: el Nuevo Centro de Población Ejidal (NCPE). En ellas, el gobierno dirigiría todas las obras de infaestructura necesaria para los programas, a la vez que se responsabilizaba del traslado de campesinos desde sus sitios de ori. gen hasta las nuevas áreas. Székely e Iván Restrepo, Frontera, 1988. dos de Campeche, Veracruz, Tabasco, Chiapas y Quintana Roo. ${ }^{4}$ Se mencionaron, igualmente, fuertes inversiones tanto para el traslado de aproximadamente 24000 familias campesinas hacia estos estados, como para poder cumplir con las promesas de "...una parcela de 50 has, casa habitación, solar urbano, escuelas, servicios de salubridad, asistencia técnica y créditos." 5

En los sexenios de los presidentes Gustavo Díaz Ordaz y Luis Echeverría se continuó con los programas de colonización dirigida hacia el sureste del país, como vía para solucionar la creciente demanda de tierra. Las entidades de Campeche, Quintana Roo y Chiapas siguieron teniendo prioridad en dichos programas. Durante esos años la prensa informó sobre traslados masivos de familias de Puebla, Michoacán, Aguascalientes, Coahuila, Tlaxcala hacia esos estados. A mediados del sexenio del presidente Echeverría empezaron a proliferar algunas críticas hacia las políticas de colonización, en el sentido de que los programas productivos que acompañaban el traslado de población ${ }^{6}$ no tomaban en cuenta las características del trópico, dando como resultado la pérdida de enormes

4 "En Campeche fueron 255000 has, principalmente en la región selvática cercana a la frontera con Guatemala; en Veracruz, 229000 has en las zonas de Martel, Las Choapas, Bocananchi y El Remolino (en el sur del estado); en Chiapas, 600000 has, la mayor parte en la comarca denominada Marqués de Comillas, fronteriza con Guatemala; en Quintana Roo, 178500 has." "Agrario", Excélsior, 30 enero 1964.

5 Ibid.

${ }^{6}$ En general dichos programas fomentaron el monocultivo y la ganadería extensiva, lo que requirió del desmonte de extensas superficies.

Martha Patricia Mendoza Ramírez 
recursos naturales y de grandes esfuerzos humanos.

Este trabajo forma parte de una investigación más amplia sobre la aplicación y adaptaciones que se hicieron a la política de colonización instrumentada en el estado de Quintana Roo, donde la reubicación de campesinos tuvo especial importancia, pues se le vio como una de las vías más apropiadas para aumentar la población y constituirlo en un estado más de la república (se erigió como entidad federativa en 1974). ${ }^{7}$ En particular, el estudio se centra en el poblamiento de la región aledaña al río Hondo, zona fronteriza con Belice y Guatemala, la cual históricamente -incluso por razones de seguridad nacional- las autoridades federales habían tratado de colonizar, con inconsistentes resultados.

LOS INTENTOS POR POBLAR QUINTANA ROO

Históricamente, uno de los principales problemas durante el proceso de configuración del estado de Quintana Roo ha sido su escaso poblamiento.

\footnotetext{
${ }^{7}$ En la gira que el presidente López Mateos llevó a cabo a finales de 1959 por Quintana Roo, declaró: "...haremos todos los esfuerzos posibles para transformar, cuanto antes, el territorio de Quintana Roo cn el estado 30 de la república y para ello es necesario cumplir requisitos constitucionales, entre ellos el de la suficiencia económica y número de habitantes. Empeñémonos ustedes y nosotros en dársela y en poblarlo con todos aquellos compatriotas que no tienen tierra en sus estados y que están ansiosos de convivir con sus hermanos de Quintana Roo". López, Construyendo, 1960.
}

Aparte de que su geografia le ha impedido a esta entidad beneficiarse con la cercanía de alguna ciudad con alta concentración demográfica o productiva, podrían citarse las siguientes razones: por un lado, las actividades económicas centrales hasta mediados de los años cincuenta fueron la explotación forestal y la extracción de chicle, labores que, en general, no fijaban a la población en los lugares de trabajo; por otro, y tal vez como consecuencia de lo anterior, la carencia de vías de comunicación. Todo esto influyó para que a mediados de la década de los cincuenta, el entonces territorio contara sólo con 27000 habitantes. $^{8}$

Vale la pena mencionar también que desde finales de la década de los veinte hubo varios intentos por trasladar población y arraigarla en el territorio, principalmente en la frontera con Belice y Guatemala. En el periodo gubernativo del general Rafael Melgar (1935-1940), una de las medidas tomadas fue la formación de centros de concentración, con los cuales se pretendía la reubicación de los pequeños poblados (de tres o cuatro familias) que se habían asentado a lo largo del río Hondo como resultado de la explotación forestal y la extracción del chicle. Las autoridades incluso prometieron dotar a los poblados, con objeto de estimular a las familias, de servicios públicos, como agua, luz y asistencia médica. Era el periodo presidencial cardenista. Algunos de estos pequeños asentamientos fueron trasladados y concentrados; se consolidaron, en-

${ }^{8}$ Galleti, Estatidad, 1994, p. 1. 
tre otros, los poblados de Allende, Sabidos, Álvaro Obregón Viejo y Pucté.?

Otra medida que se intentó en este periodo fue el traslado de población de otros estados hacia dos zonas de Quintana Roo. La primera, ubicada al sur del estado de Yucatán; la segunda, en la ribera del río Hondo. Sin embargo, tales intentos no fructificaron ya que no lograron el arraigo esperado de pobladores. En los gobiernos posteriores, el del general Gabriel R. Guevara y el de Margarito Ramírez, prácticamente estos programas se abandonaron.

Más tarde, en el periodo gubernativo de Aarón Merino Fernández (19581964), y siguiendo - como decíamoslas políticas de colonización dirigida emprendidas por el presidente López Mateos, pero sobre todo para convertir al entonces territorio de Quintana Roo en el estado número 30 del país, se revitalizó el traslado de población hacia esta región. ${ }^{10}$ Se realizó una fuer-

\footnotetext{
9 Centro de Investigaciones de Quintana Roo (en adelante ClQkoo), Estudio, 1993.

${ }^{10}$ En un documento de la época se menciona: "De conformidad con los propósitos del presente régimen de que el territorio de Quintana Roo se convierta en estado, para cuyo efecto deberá estimularse el crecimiento de la población en dicho territorio para lograr el fin indicado, el Departamento de Asuntos Agrarios y Colonización ha proyectado colonizar en gran escala una vasta región de aquel territorio, en los lugares susceptibles al cultivo y de crear centros ganaderos y forestales.

"Para tal propósito se ha planeado el traslado gradual de masas campesinas con derechos agrarios a salvo, a razón de 10000 personas por cada uno de los años de 1962, 1963 y 1964, efectuándose los referidos traslados a medida que vayan realizándose las construcciones de casas y los deslindes de las tierras colonizables, a efecto de
}

te campaña a través de la prensa y el radio invitando a todo campesino sin tierra a ir a Quintana Roo. Entonces se definieron tres zonas susceptibles de colonización. La primera se ubicó al noroeste del estado, en la parte que limita con el sureste de Yucatán. La segunda se estableció en Bacalar, al sur, y la tercera se localizó en la margen izquierda del río Hondo, limitando con Belice hasta llegar a la frontera con Guatemala.

A esta última zona se le dio mayor importancia dentro de los planes de colonización, formándose nueve Nuevos Centros de Población Ejidal (NCPE), tales como Calderitas, Reforma Agraria, Huay Pix, Xul-Há, Bacalar, José María Morelos (Cafetal), Caobas, Álvaro Obregón y Laguna Guerrero, adonde se trasladó población de varios estados del país. Sin embargo, la improvisación al emprender estos programas,

que los campesinos empiecen a trabajar las tierras inmediatamente después de su llegada y cuenten con los albergues necesarios para ellos y sus familias.

"Durante el año de 1962 se ha proyectado la creación de 33 centros de población, considerándose 60 jefes de familia y 300 personas para cada uno de dichos centros y señalándose lotes de 50 has para cada jefe de familia.

"La superficie que se ha considerado necesaria para el sostenimiento de una población de 10000 personas se ha calculado en aproximadamente 100000 has, de las cuales 70000 se destinarán para explotación forestal, 20000 para explotación ganadera y 10000 para agricultura, debido a la característica natural de las tierras de aquella región."

El monto de la inversión requerida para 1962 era de alrededor de $37 \mathrm{mil}$ millones de pesos. Archivo General de la Nación (en adelante AGN), ramo Presidentes, exp. Programa de inversiones para la colonización del territorio de Quintana Roo, 8 noviembre 1961. 
y la falta de medidas que propiciaran el arraigo, provocó de nueva cuenta que la mayor parte de la población trasladada regresara a sus lugares de origen. ${ }^{11}$

Con la llegada de Luis Echeverría a la presidencia de la república se da un verdadero impulso a las políticas de colonización dirigida en el territorio. ${ }^{12}$ A lo largo de este periodo fueron trásladados cientos de campesinos de Michoacán, Veracruz, Coahuila y Tabasco, entre otros. La principal zona por colonizar dentro del estado siguió siendo la aledaña al río Hondo, en la frontera con Belice y Guatemala. Ya para finalizar el gobierno del presidente Echeverria, se diseñó el Plan de Colonización del Sudeste, mediante el cual 50000 personas serían trasladadas principalmente a Campeche y a Quintana Roo. ${ }^{13}$ En este último estado la zona fronteriza siguió teniendo prioridad y con una inversión enorme se anunció la consolidación de 10 Nuevos Centros de Población Ejidal que fueron, Nicolás Bravo, Pedro Peralta,

11 Álvarez, Historia, 1971.

12 "En 1971 se integró la Comisión Intersecretarial de Nuevos Centros de Población Ejidal (COINCE), para promover la colonización en algunos lugares del norte y del sureste. Con este fin, se establecieron dos 'cuencas de colonización'. Una que abarca la franja de $100 \mathrm{~km}$, a lo largo de la frontera con Estados Unidos; la otra, que comprende el Valle de Edzná en Campeche, la Cuenca del Ucum en Quintana Roo, y Punto Put en la confluencia de los límites de estas entidades con Yucatán", Székely, Frontera, 1988, p. 32.

${ }^{13}$ Con este nuevo plan de colonización se anunció en una primera etapa el traslado de 10000 familias campesinas, distribuidas en 20 poblados de 500 familias cada uno. Se ubicarían en Campeche (10) y en Quintana Roo (10). "Programa", Excélsior, 15 enero 1975, pp. 1-9.
Palmar, Morocoy, Ramonal, Sacxán (Carlos A. Madrazo), Sergio Butrón, Bacalar, Juan Sarabia y Allende.

Así se cumplía, después de varios intentos, con uno de los principales objetivos de la colonización dirigida: el de reforzar la frontera, lugar estratégico para el gobierno mexicano. Es en esta zona fronteriza donde centramos el presente trabajo.

\section{La Formación de los Nuevos Centros DE POBlaCión EjIDAl (NCPE)}

Cada Nuevo Centro de Población Ejidal fue pensado como un "polo de desarrollo", cuyo crecimiento generaría beneficios para las poblaciones aledañas. Lograr lo anterior era una de las tareas primordiales de la Comisión Intersectorial de Nuevos Centros de Población Ejidal (COINCE), que promovía la participación de las instituciones y organismos gubernamentales, durante la puesta en marcha de cada nuevo centro, para la solución de problemas tales como la construcción de carreteras, electrificación, suministro de agua potable, construcción de casas, escuelas, hospitales, etcétera. ${ }^{14}$

14 Un ejemplo de esto puede verse en el establecimiento del NCPE Guadalajara, donde se convoca a todas y cada una de la secretarías y organismos gubernamentales a participar en su formación:

"Que a efecto de crear la infraestructura económica y social indispensable para el sostenimiento y desarrollo del núcleo que constituirá el NCPE Guadalajara, así como lo relativo al traslado de campesinos de su lugar de origen al de su destino, los servicios y comunicaciones, la apertura de tierras al cultivo con los elementos crediticios y asesoría técnica indispensable, 
En la construcción de cada una de estas obras, así como en los primeros desmontes, los nuevos colonos proporcionaban la mano de obra necesaria.

De diez a doce meses dura el desmonte y la construcción del pueblo. Durante ese lapso, los jefes de familia permanecen solos, sin su mujer o sus hijos, y reciben una ayuda salario de 25 pesos diarios, por cinco pesos se les proporcionan en el campamento los tres alimentos.

Mediante el sistema de autoayuda los campesinos construyen su propias casas. Una vez definidas las responsabi-

deberán intervenir las siguientes dependencias: SCHP, con las ampliaciones presupuestales a las partidas relativas a creación de NCPE, Secretaría de la Presidencia, con coordinación y asesoramiento indispensable, la SRH para los estudios geohidrológicos y obras necesarias para obte. ner el agua tanto para usos domésticos, como para establecer unidades de riego en su caso; la SSA, para el establecimiento de hospitales o casas de salud, unidades de agua y red de agua potable; la SEP para la construcción de escuelas y contratación de maestros; la SAG, con objeto de que asesore a los campesinos en el desarrollo agrícola y ganadero; la soP a fin de que construya las obras indispensables para que se cuente con las vías de acceso necesarias; la SCT para la instalación de servicios de correo y telégrafo; el Instituto Nacional para el Desarrollo de la Comunidad Rural y de la Vivienda Popular a fin de asesorar campesinos; la CFE, que introduzca energía eléctrica; CONASUPO, para la organización de cooperativas e instalación de tiendas; $y$ los Bancos Oficiales de Crédito a fin de que los beneficiados queden organizados en sociedad y se les proporcionen los créditos indispensables para eí desmonte de tierras, mecanización, etc., y el gobierno de la entidad federativa en donde quedará instalado el nuevo centro de población...", "Establecimiento del nuevo centro de población ejidal (NCPE), en Guadalajara", Diario Oficial de la Federación, 17 julio 1972. lidades de cada quien, elaborado el programa de producción agrícola o ganadero, esto es a la vuelta de un año, cada quien trae a su familia. ${ }^{15}$

Si bien en México se "resolvían" todos los detalles para el establecimiento y buen funcionamiento de cada nuevo centro de población, ${ }^{16}$ en la zona de colonización la situación que imperaba era otra, caracterizada por la poca coordinación entre las instituciones, su desconocimiento total de las características sociales y naturales de la región, la confusión en los términos del traslado ${ }^{17}$ y la omisión de la población nativa en los programas que

15 "Programa", Excélsior, 15 enero 1975.

${ }^{16}$ Incluso se llegó a situaciones extremas, como solicitar que a los colonos se les confeccionara la ropa necesaria durante el tiempo que durara la construcción de sus casas.

17 Desde sus inicios, los programas de colonización en el estado de Quintana Roo, se caracterizaron por la confusión y escasa claridad con que el entonces Departamento de Asuntos Agratios y Colonización, y más tarde la Secretaria de la Reforma Agraria, efectuaron el traslado y ubicación de los nuevos colonos. Así, en algunas ocasiones se hablaba de la formación de un Nuevo Centro de Población (NCPE); en otro, se trataba de la creación de "anexos", es decir, de una nueva zona urbana dentro de un ejido ya constituido, o bien, los colonos eran tratados como repobladores (ocupar plazas vacantes dentro de los ejidos ya establecidos). Ello al parecer repercutió en la ayuda prometida a los colonos, pues por los datos que hasta ahora tenemos, la mayor parte de las inversiones se destinaron a los NCPE o bien a los "anexos", quedando poco o casi nada para los llamados "repobladores". Es necesario aclarar que si bien se decía que un "anexo" era solamente una nueva zona urbana dentro de un ejido ya establecido, al momento de contratar algún crédito u otro tipo de asistencia, el "anexo" era tratado de manera independiente al ejido. 
se estaban llevando a cabo, los cuales afectarian sus tierras.

Todos estos problemas causaron por lo general, retrasos en las obras, ${ }^{18}$ e incumplimiento de las promesas hechas para llegar a esas tierras (se les prometía casa, tierra para trabajar, apoyos crediticios, etcétera) ${ }^{19}$, por lo que

${ }^{18}$ En 1976, el entonces subsecretario de los NCPE de la SRA, Pedro Vázquez Colmenares, recorrió cuatro centros de población de la ribera del río Hondo, en los cuales se evidenció la falta de coordinación entre las dependencias encargadas de ejecutar la obras. "Esta situación -dijo-se ve como retardataria del desarrollo del área pese a los esfuerzos y dinero invertidos, entre 50 millones de la Reforma Agraria.

"Agregó que la colonización no es una actividad que pueda realizar por sí sola una determinada dependencia del poder ejecutivo. Es necesaria la participación de todas las dependencias federales en coordinación con los propios pobladores.

"En el recorrido por Sergio Butrón Casas, Carlos A. Madrazo, Botes y José N. Rovirosa se planteó la falta de agua potable y la necesidad de contar con riego para los sembradios de arroz y otros cultivos..." "Falta", Novedades de Quintana Roo, 8 noviembre 1976.

19 El caso del NCPE de Morocoy es ilustrativo de esta situación. "Unos 70 ejidatarios del NCPE llamado Morocoy, efectuaron una manifestación desde la entrada de la ciudad hasta el Palacio de Gobierno, para exigir el cumplimiento de varias promesas $[\ldots]$ por parte de las autoridades gubernamentales.

"Entre las peticiones que los ejidatarios hicieron se cuenta la construcción de caminos de acceso para sacar de los campos las cosechas; la dotación de maquinaria para la trilla de arroz, la construcción de un pozo y la red de agua potable del lugar y la resolución para que se les prepare parte del terreno mecanizado que que. dó pendiente el año pasado y poderlo trabajar en el ciclo 80-81. También pidieron la dotación de maquinaria para su ejido, la dotación de servicio médico para la atención de sus familias, la pavimentación del camino que comunica al poblado con la carretera asfaltada y la realización del deslinde del ejido. muchos colonos regresaron a sus lugares de origen, con la consecuente pérdida de recursos materiales y de trabajo humano. ${ }^{20}$ Además, algo digno de destacar es que el traslado de población provocó enfrentamientos fuertes con la población nativa.

\section{LOS CONFLICTOS POR LA TIERRA. PRIMEROS EFECTOS DE IAA COLONIZACIÓN DIRIGIDA}

Un rasgo de la colonización en Quintana Roo que causó graves conflictos entre colonos, la población nativa y funcionarios de Reforma Agraria, fue que la mayor parte de los NCPE O anexos ubicados en la zona del río Hondo, se establecieron en lo que Reforma Agraria llamó tierras "excedentes" de los hasta entonces ejidos forestales. Dichos poblados se formaron principalmente durante el periodo presidencial del general Lázaro Cárdenas. Sin embargo, debido a la sobreexplotación de los bosques y a los efectos del ciclón Janet (1955), todos estos pobla-

"Una por una las peticiones de los ejidatarios fueron discutidas entre los manifestantes y los representantes de la dependencias gubernamentales borrándose, de esa manera, los rasgos de hostilidad que en un principio se observaron." "Ejidatarios", Novedades de Quintana Roo, 22 agosto 1979.

${ }^{20} \mathrm{El}$ ir y venir de población fue una constante dentro de los programas de colonización hasta finales de los años setenta. Esta situación provocó fuertes pérdidas materiales, pues se abandonaban obras casi concluidas como fue el caso de las casas construidas en el poblado de Ucum, cuyos pobladores regresaron a sus luga. res de origen. Igualmente, la inestabilidad de la población provocó retrasos en el otorgamiento de créditos y ayuda para quienes se quedaban. 


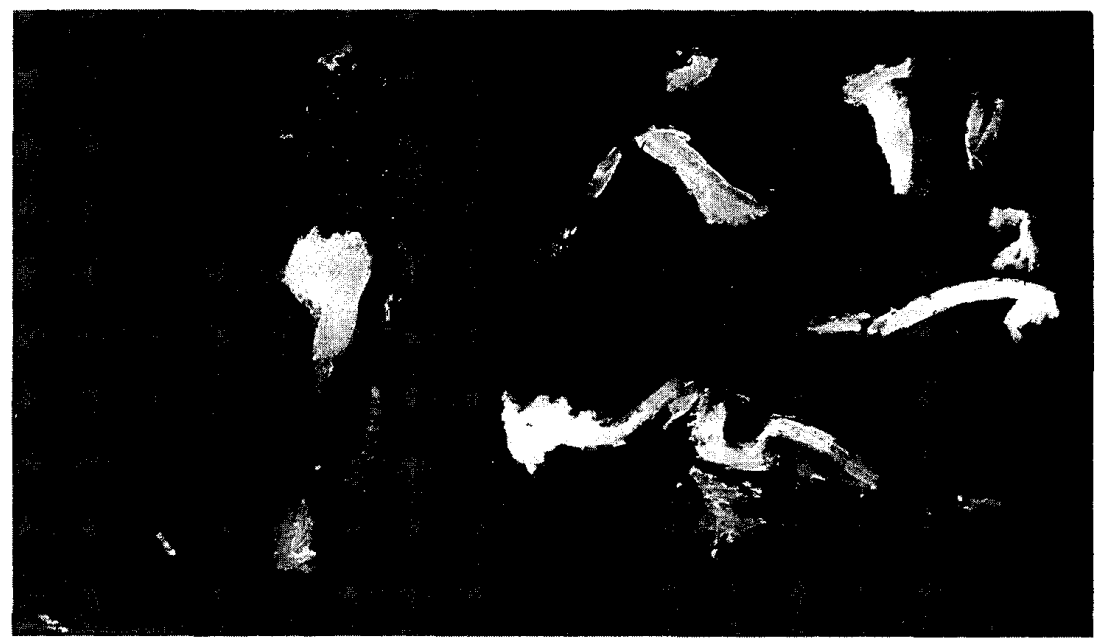

dos ya no contaban con madera suficiente para una explotación rentable.

Sin embargo, estas tierras que Reforma Agraria calificaba como "excedentes" representaban para los ejidatarios parte de su patrimonio, pues servirían para dotar a futuras generaciones. La población nativa se enteró la mayoría de las veces "en los hechos" de que parte de sus tierras se destinarían a cientos de nuevos pobladores, mediante la construcción de un centro de población o de un "anexo", o que a su ejido llegarían cientos de campesinos de otras regiones a ocupar las plazas vacantes.

Tales fueron los casos de los poblados de Botes,Álvaro Obregón y Sacxán, que en los primeros años de la década de los setenta fueron ocupados. En los dos primeros, los ejidatarios se enteraron de que por resolución presidencial parte de sus tierras servirían para albergar a cientos de campesinos venidos de fuera (207 en Botes y 139 en Álvaro Obregón). ${ }^{21}$ En el poblado de Sacxán, funcionarios de la Reforma Agraria realizaron varias asambleas y debieron prometer gran ayuda para que se aceptara a 100 colonos que ya no tuvieron cupo en el ejido de Botes, formándose así el anexo Carlos $\mathrm{A}$. Madrazo. ${ }^{22}$ Años más tarde nuevamen-

21 Por resolución presidencial de Luis Echeverria, firmada el 7 de mayo de 1976, se beneficiaba a 222 campesinos procedentes de la Comarca Lagunera con tierras del ejido de Botes.

22 El informe del Comisionado Promotor de 
te parte de las tierras de este poblado se destinaron a formar el NCPE Sergio Butrón Casas.

Esta forma de actuar derivó en conflictos fuertes entre ejidatarios y funcionarios de Reforma Agraria, como los suscitados en los ejidos de Botes y Álvaro Obregón, donde los nativos se ampararon en contra de la decisión presidencial y se negaron a recibir cual-

Nuevos Centros de Población al Delegado Agrario del DAAyc, es ilustrativo de esta situación:

"Con fecha 7 del (mes de julio de 1974) me trasladé al poblado de Sacxán, Quintana Roo, con el objeto de reunirme con los ejidatarios del lugar e iniciar labor de convencimiento para que aceptaran a un grupo de aproximadamente 100 campesinos procedentes de la Comarca Lagunera y unidos ambos estuvieran en posibilidad de ampliar a ese poblado el programa de Nuevos Centros de Población, con el cual se beneficiarian grandemente, ya que uno de los beneficios del mismo, sería la construcción de sus casas-habitación, desde luego con la aportación de la mano de obra de los ejidatarios, sin que en esta ocasión se hubiese levantado votación.

"Posteriormente con fecha 12 del propio mes y año, pero en esta ocasión acompañado por el secretario de la Liga de Comunidades Agrarias y Sindicatos Campesinos, el representante de la Delegación Agraria, el residente de NCPE respectivamente, nuevamente hicimos labor de convencimiento, no habiendo podido levantar también en esta ocasión votación alguna.

"Fue hasta el domingo 21 del citado mes de julio, del año en curso, en que acompañado de los mismos ciudadanos citados anteriormente [...] que los ejidatarios aceptaron el reacomodo y el Programa de Nuevos Centros de Población Ejidal.

"[...]los ejidatarios aceptaron el reacomodo pero deberán tener prioridad los hijos de los campesinos mayores de 16 años, sobre los campesinos reacomodados, al practicarse la depuración censal en este poblado". Archivo de la Secretaría de la Reforma Agraria (en adelante ASRA), ejido Sacxán, exp. Derechos agrarios, 23 julio 1974. quier ayuda gubernamental, mientras no se resolviera la situación; ${ }^{23}$ o bien los enfrentamientos que se dieron entre funcionarios de esa secretaría y ejidatarios de Sacxán en 1974, como lo muestra el siguiente expediente:

Del comisariado ejidal de Sacxán al delegado de Reforma Agraria:

23 "Los amparos fueron promovidos los días 5 y 11 de noviembre (1976) por los comisariados ejidales de San Francisco Botes y Álvaro Obregón respectivamente.

"En sus demandas los citados poblados responzabilizan tanto al presidente de la república de aquel entonces, como a las autoridades agrarias de la nación y de la entidad, de haber dictado y ejecutado una resolución presidencial de derechos agrarios que no estuvo apegada a lo que marca la ley.

"En el amparo [...] las autoridades ejidales [de Botes denuncian] que la resolución se dictó sin que jamás se hubiera expedido covocatoria o se hubiera celebrado asamblea general como lo establece la ley.

"Reclaman que en cumplimiento a una resolución presidencial de fecha 19 de julio de 1976 se hubiera dado posesión en una fracción de su ejido a un total de 207 campesinos venidos del interior de la república a colonizar Quintana Roo.

"También reclaman de las autoridades a las que han responzabilizado, las órdenes que han girado para que se les siga despojando parcialmente de los terrenos de su ejido, no obstante que, según expresan, éstas les fueron dotadas por resolución presidencial, la cual es inmodi. ficable.

"En el amparo promovido (por las autoridades de Álvaro Obregón) se reclama que se les está despojando de 1500 has de su ejido por parte de las autoridades agrarias, al querer éstas darle indebida ejecución a una resolución presidencial.

"En esa demanda de amparo, los representantes del ejido reclaman el reacomodo indebido que pretende dársele a 139 colonos venidos del interior de la república.."Amparo", Novedades de Quintana Roo, 8 marzo 1977. 
Por este conducto nos permitimos manifestar nuestra inconformidad por el procedimiento seguido, al acomodar "colonos" en terrenos que corresponden al nuestro, sin que previamente se nos haya puesto en conocimiento, aclaramos que esa no es la manera legal de actuar de una delegación de la Reforma Agraria, dando posesión a otros, sin que con nuestra organización ejidal se haya tomado algún acuerdo ni que hayamos dado nuestra conformidad.

Recalcamos que han dado acomodo a "colonos", sin tener acuerdos legales con los ejidos vecinos y ponerse de acuerdo para los deslindes correspondientes. Es mal procedimiento repartir y dar acomodamiento[sic], como se ha venido haciendo ya que esto podría traer consecuencias fatales tanto para uno como para otro bando.

Fuimos dotados de nuestro ejido por el general Cárdenas y tenemos nuestros derechos agrarios legalmente reconocidos [...] a pesar de que esa dependencia a su cargo ha negado en ocasiones anteriores a nuestros representantes ejidales copias fotostáticas del acta de posesión y del plano de nuestro ejido que sabemos existen en los archivos de Reforma Agraria.

La invasión de que fuimos objeto por parte de los colonos de Butrón Casas ud. la supo, pero a pesar de todo ud. escurre el bulto y nos trae vuelta y vuelta', más aún sabiendo que fuimos amenazados de muerte (con máuseres de la federación) por los rurales de Butrón y éstos, aún siguen patrullando su ejido fuertemente armados, y en caso de suscitarse un hecho de sangre ud. será el directamente culpable.

[...] exigimos se estudie el caso para que no sigan cometiendo injusticias con nosotros los viejos ejidatarios.

Sr. delegado, recuerde bien sus palabras, que fueron, que toda la super- ficie que quedara dentro de nuestro ejido no sería tocada en lo absoluto, esa fue su promesa y ahora tal parece que su palabra no tiene validez, puesto que ahora se están metiendo a nuestro monte alto y nos había dicho que únicamente sería dotado Butrón del bajo conocido con el nombre de Bajo de Acatucha $y$ las brechas indican sin lugar a dudas, que sí hay invasión.

Sacxán está amparando a 67 ejida. tarios del poblado, más otros repobladores de Ucum y 250 de Carlos A. Madrazo. ${ }^{24}$

Junto a la problemática agraria que causó la colonización, ocurrieron igualmente enfrentamientos entre los colonos y la población nativa por la organización interna del ejido (nombramiento de autoridades) ${ }^{25}$ y por la producción. En cuanto a lo primero, los recién llegados insistieron en nombrar sus propias autoridades ejidales, desconociendo las existentes. Respecto a la producción, los colonos fueron incorporados de lleno a cultivos comerciales, para lo cual gozaron de créditos y apoyos en obras de infraestructura, a diferencia de la población nativa, que fue quedando marginada de estos beneficios. Ambos problemas ocasionaron mayores protestas por parte de la población nativa.

${ }^{24}$ ASRA, ejido Sácxán, exp. Dotación, 5 diciembre 1976.

${ }^{25}$ Los ejemplos en este sentido son varios. En 1962, los recién llegados al poblado de Ucum se negaban a reconocer como autoridades al comisariado ejidal de Sacxán; igualmente, en 1974 los colonos del anexo Rovirosa en el ejido de Botes, pretendieron nombrar sus propias autoridades ejidales. 
Al agudizarse los conflictos no faltaron, desde luego, las voces en el interior del estado de Quintana Roo, censurando la forma en que se llevaban a cabo los programas de colonización. ${ }^{26}$ Fue entonces cuando el gobernador Jesús Martínez Ross "exigió" que los beneficios de dichos programas se extendieran a la población nativa, es-

26 "Es aterrador observar la gran cantidad de carencias y condiciones de vida en que viven los habitantes de diferentes comunidades del estado, que tienen 15 o 20 años radicando en esta tierra, o que son nativos, en tanto que otras personas por el solo hecho de aportar su presen. cia se les trata en bandeja de oro.

"Esto ha creado un sentimiento discriminatorio y la proliferación de líderes que desconocen los verdaderos problemas locales, pero que sirven a intereses mezquinos y ajenos a los campesinos $^{n}$, dijo el entonces candidato a diputado federal Gómez Barrera.

"Agregó: Se ha marginado a los lugareños, que sí han aportado algo a Quintana Roo, en tanto que se han proporcionado todas las condiciones necesarias y a veces exigentes a gente que ha venido de otros lugares, $y$ no sabemos cómo se haya seleccionado, aunque la lógica hace suponer que es gente que no ha podido resolver sus propios problemas en sus lugares de origen, en donde carecían de todo, principalmente de tierras.

"Estos movimientos que se hicieron necesarios para cubrir dos importantes requisitos para la transformación de Quintana Roo en estado pueden ocasionar serios problemas y llegar a fricciones y a choques de no atenderse a tiempo y con sentido humano.

"...es necesario hacer un llamado a las auto. ridades correspondientes para que se haga una revisión de la política de colonización y estos programas se lleven a cabo de una forma mejor planeada.

"Debe evitarse el centralismo, ya que no es posible que los titulares de las dependencias oficiales federales, puedan resolver problemas que desconocen". "Critica", Novedades de Quintana Roo, 24 junio 1976, p. 1. pecialmente los relacionados con la construcción de casas y con los apoyos a la producción. Se pedía que la colonización fuera "mixta". A partir de entonces, varios ejidos de la ribera del río Hondo fueron incorporados, sobre todo, a los programas de construcción de casas.

\section{UN CAMBIO EN EL PATRÓN DE CULTIVOS}

Como mencionamos al principio, el traslado de población se acompañó con fuertes inversiones, tanto en el aspecto productivo como en obras de infraestructura, privilegiándose igualmente el apoyo a cultivos comerciales. En Quintana Roo el cultivo de arroz fue el primero en recibir apoyos fuertes para su producción. La zona de cultivo se ubicó principalmente en los terrenos de Sergio Butrón Casas y Carlos A. Madrazo, de quienes se decía que llegarian a ser los productores arroceros del país.

Como resultado del gran triunfalismo con que se manejó este programa (respuesta a la escasez mundial de alimentos, etcétera) así como por la instalación de un molino de arroz, ${ }^{27}$ se fue incorporando a los demás pobla-

27 Dicho molino sería instalado en el NCPI de Sergio Butrón Casas y alimentado con la producción de los nuevos centros de población ubicados en la cuenca del valle uCuM, y ejidos de la región.

El molino se calculó con una capacidad de 15000 tas y debería beneficiar principalmente a los NCPE de Carlos A. Madrazo y Sergio Butrón Casas, a los que se consideraba los principales arroceros de la entidad. Su costo se calculó en 20 millones de pesos. "Ahora", Novedades de Quintana Roo, 23 mayo 1976. 
dos de la región. Para lograrlo, se condicionaron los créditos a la siembra de este producto. Muchos ejidatarios protestaron y aseguraron que esas tierras no eran aptas para ese cultivo y pedían continuar con sus cultivos tradicionales; tal fue el caso de los ejidatarios de Álvaro Obregón, que solicitaban continuar con la siembra de maíz. Sin em. bargo, dichas advertencias no fueron tomadas en cuenta.

Años más tarde, por factores como el retraso en las Iluvias, la mala calidad de los suelos, los problemas en el otorgamiento de créditos y la escasa asistencia técnica, los cuales provocaban constantes retrasos en la siembra del arroz que obviamente repercutían en las cantidades cosechadas, ${ }^{28}$ este

${ }^{28}$ Estos son algunos ejemplos que se rescatan de la prensa quintanarroense:

"Los colonos de Carlos A. Madrazo sembra. ron 868 has de arroz, pero debido a circunstancias fuera de su control -el retraso de tres meses en las lluvias, entre ellas- suffrieron pérdidas totales en 435 has..." "Reconsideran", Novedades de Quintana Roo, 9 febrero 1976.

"De dos promesas hechas por el Banco de Crédito Rural Peninsular en un lapso de seis meses a la Sociedad Local de Crédito Ejidal de Carlos A. Madrazo, ninguna se ha cumplido dejando a 250 ejidatarios en la triste 'espera' $y$ han motivado que la siembra de arroz se retrase...

"La primera promesa del banco fue el proporcionar once tractores como crédito refaccionario. De esos once tractotes sólo tres fueron entregados.

"Los campesinos de Carlos A. Madrazo después hicieron una nueva petición, que se les porporcionara un crédito para la reparación de los tres tractores con los que cuentan y que están en mal estado. El crédito les fue negado. Los ejidatarios informaron que sus siembras se retrasarán debido a que sus tractores se encuentran en mal estado y que no pueden preparar la tierra para que el 1 de abril den inicio a la primer intento de cultivar arroz en gran escala fracasó rotundamente. ${ }^{29}$

La caña de azúcar fue el cultivo alternativo a la siembra de arroz, y nuevamente se habló de las grandes potencialidades de los suelos, ${ }^{30}$ de la buenas condiciones climáticas, etcétera. Se proyectó la instalación de un ingenio azucarero en los límites de los ejidos de Pucté y Álvaro Obregón y se empezó a reiterar la necesidad de sembrar cientos de hectáreas con caña de azúcar. Se tenía proyectado la siembra de 12000 has ubicadas en los poblados de Álvaro Obregón, Pucté, Allende, Cocoyol, Pucté, Botes, Cacao, Sabidos.

Los NCPE Sergio Butrón y Carlos A. Madrazo $^{31}$ quedaban fuera del área de

siembra de 2300 has de arroz." "Falta", Novedades de Quintana Roo, 12 febrero 1977.

"I a excesiva humedad de los suelos impide la preparación de los terrenios, lo que una vez más provocará retrasos en la siembra de arroz, principalmente en 250 has de José N. Rovirosa, 2000 has de Carlos A. Madrazo y 1000 has en Sergio Butrón Casas." "Excesiva", Novedades de Quintana Roo, 16 marzo 1977.

29 '[...]'Ia triste experiencia' obtenida a to largo de tres ciclos fue señalada por ejidatarios de Sergio Butrón Casas quienes ya no quieren continuar sembrando arroz...

"[...]desalentados, ejidatarios de Sergio Butrón dijeron no querer seguir sembrando arroz pues en lo que algún día pudo haber sido un sustento para Quintana Roo, se registraron grandes pérdidas por lo que han solicitado a las autoridades correspondientes se diversifiquen sus cultivos.

"[...]en tres ciclos se han sembrado 12000 has de las cuales se han cosechado mil..." "Arroz" Novedades de Quintana Roo, 26 agosto 1977.

${ }^{30}$ De hecho este era el segundo intento para sembrar la caña de azúcar; la primera experiencia se había dado a principios de los años sesenta.

${ }^{31}$ La importancia de estos dos centros es que representaban $50 \%$ de la tierra mecanizada. 
acción del ingenio $(20 \mathrm{kms})$, por lo que al principio no fueron contemplados en el programa cañero. Sin embargo, ante el total fracaso del cultivo de arroz en ambos poblados, la caña de azúcar se vio como la única opción viable.

El entonces gobernador Jesús Martínez Ross intervino para que estos dos NCPE fueran incorporados al programa cañero, ${ }^{32}$ comprometiéndo-

32 "El gobernador del estado, Jesús Martínez Ross, propondrá al secretario de la SARH un proyecto para el aprovechamiento de un amplio sector de esa entidad que desde 1974 ha sido poblado por colonos del centro del país...

"Sergio Butrón Casas y Carlos A. Madrazo son dos NCPE que ocupan parte de la cuenca de Ucum, considerada una de las mejores superficies potencialmente hablando.

"Informó el gobernador que en esa zona se han invertido millones de pesos para el cultivo de arroz y han habido pérdidas considerables debido a la variabilidad del tiempo.

"La propuesta que traemos está elaborada con base en estudios detallados sobre la zona que se han venido realizando con el objeto de buscar actividades rentables para las $750 \mathrm{fami}$ lias que habitan los dos centros de población.

"Ross dijo que básicamente se propone la construcción de obras complementarias (obras de riego), la diversificación de cultivos y principalmente la siembra de 3000 has de azúcar, a pesar de las opiniones contrarias a esto.

"Aunque muchas opiniones se han opuesto a que se cultive caña en superficies que se encuentran a más de $20 \mathrm{~km}$ de distancia de la zona cañera, los logros que hemos obtenido en 13 has de Madrazo, nos permiten proponer el cultivo de 3000 has en Butrón y Madrazo que se hallan a $25 \mathrm{~km}$ del ingenio.

"Con base en varios estudios se considera que todavía es rentable el cultivo de caña en estos centros, además de que la caña resiste a diferencia de otros cultivos tanto la sequía como el exceso de humedad." "Pedirá", Novedades de Quintana Roo, 9 noviembre 1977. se a ordenar la construcción de obras para riegoy de una carretera que redujera la distancia al ingenio. Igualmente, se firmó un convenio con la Comisión Nacional de la Industria Azucarera, en el que dicho organismo se comprometía a comprar toda la producción de caña de ambos centros, siempre y cuando el Banco de Crédito Rural otorgara los créditos para la siembra. ${ }^{33}$ Según este convenio, se sembrarían 2000 has en Sergio Butrón y 1000 en Carlos A. Madrazo. ${ }^{34}$

Cientos y cientos de hectáreas empezaron a ser sembradas con caña de azúcar dentro de la zona de abastecimiento del ingenio; año con año se hablaba de la incorporación de nuevas zonas para este cultivo. Sin embargo, la puesta en marcha del ingenio se retrasó año con año (la primera zafra se programó para 1975 y se realizó hasta finales de 1978) con la consecuente pérdida para los ejidatarios. El siguiente texto es ilustrativo de esta situación:

No habrá zafra de prueba ahora (febrero de 1978), como no la hubo en enero y como tampoco la hubo en diciembre porque el ingenio azucarero de Álvaro Obregón, que aparentemente ha sido concluido tiene numerosas fallas que es preciso corregir.

[...]técnicos de la Comisión Nacional de la Industria Azucarera (llegaron al ingenio) para una operación de prueba del enorme complejo industrial.

33 La Comisión Nacional de la Industria Azucarera otorgaba los créditos para la siembra de caña con la condición de que quedaran dentro de un radio de acción de $20 \mathrm{~km}$ del ingenio.

34 "Comisión" Novedades de Quintana Roo, 12 noviembre 1977. 


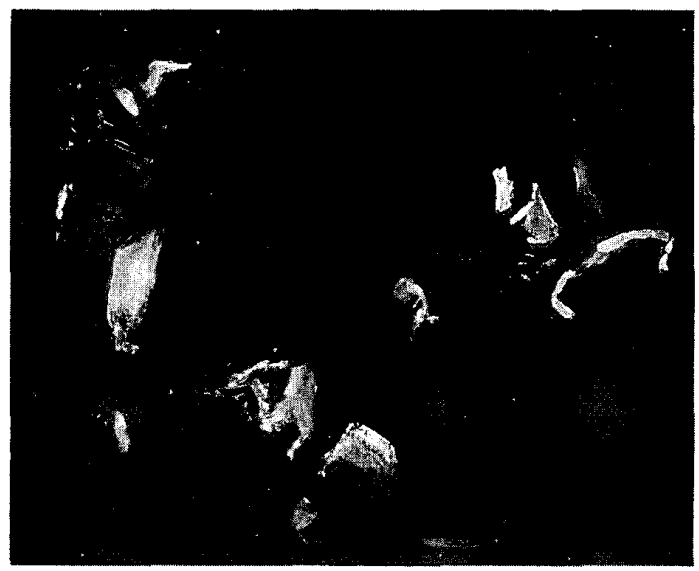

La prueba iba a realizarse en secreto [...] pues como se recordará el ingenio ha sido duramente criticado por el tiempo que ha tardado construirlo, por la enorme inversión que ha significado y porque desde hace tres años mantiene en un estado de tensión nerviosa a los campesinos cañeros que hasta hoy no saben del pago de la caña que han sembrado, que se ha perdido y que adeudan al Banco de Crédito Rural.

Según trascendió, la prueba fue un rotundo fracaso. Cuando las seis calderas recibieron la mitad de la presión que de ordinario han de soportar para mover todo el complejo, brotaron fugas por todos lados.

[...]los técnicos concedieron ocho meses más a la Operadora Nacional de Ingenios Azucareros (ONISA) y a sus contratistas, para que reparen las fallas y pongan en movimiento el ingenio azucarero.

Esto quiere decir que la zafra de prueba, que originalmente fue programada para el 75 , que fue pospuesta después para el 76 cuando para distraer la atención, el entonces presidente Echeverría lo inauguró simbólicamente, y después para diciembre del 77 y más tarde para enero del 78 que acaba de fracasar rotundamente, se efectuará hasta agosto. Si no surgen contratiempos.

La preocupación de los ejidatarios cañeros se justifica pues si tomamos en cuenta que hace tres años siembran caña que no les ha comprado el ingenio y que consecuentemente adeudan al Banrural.

Los ejidatarios reciben 7000 pesos en crédito para la siembra de cada hectárea. Se supone que al vender su producto al ingenio pagan su adeudo con el 
Banco y obtienen alguna ganancia. Pero no ha sido así en los últimos tres años. ${ }^{35}$

Al final, la primera zafra se realizó hasta 1979. Sin embargo, hasta 1982 el ingenio trabajaba apenas a $28 \%$ de su capacidad. ${ }^{36}$

\section{CONCLUSIONES}

Si bien con los programas de colonización se logró poblar la ribera del río Hondo, que era una de las principales preocupaciones del gobierno federal, los resultados de dichos programas en los aspectos económico, social y natural han sido francamente negativos.

El cambio en el patrón de cultivo, el apoyo a la siembra de arroz y la de caña de azúcar, no han dado los resultados esperados y se sigue hoy hablando de grandes pérdidas en estos productos con el consecuente detrimento en la economía de los productores. En cuanto a la ganadería, los resultados han sido igualmente negativos; se habla de poner en marcha un nuevo proyecto para utilizar las miles y miles hectáreas de pastizales que se encuentran ociosas.

Por otra parte, el apoyo al monocultivo pero sobre todo a la ganadería extensiva, que requieren del desmonte de cientos de hectáreas, ha ocasionado en gran parte el grave problema de deforestación que hoy se vive en este estado. En un estudio se menciona que en poco menos de 20 años la 1978.

${ }^{35}$ Novedades de Quintana Roo, 5 febrero

36 Macías, "Transformaciones", Formación, 1985, p. 296.

LA COLONIZACIÓN DE LA FRONTERA SUR superficie de selvas primarias o moderadamente alteradas se redujo a $30 \%$ de su extensión original. ${ }^{37}$

Finalmente, en el aspecto social, al no cumplirse las promesas de un mejor nivel de vida, existe hoy una fuerte migración de campesinos de estos centros de población hacia las ciudades de Cancún y Chetumal, principalmente.

\section{BiBLIOGRAFÍA:}

-Álvarez Coral, Juan, Historia de Quintana Roo a partir de la guerra de castas, Gobierno de Quintana Roo, México, 1971.

-Casco Montoya, Rosario, Los planes de desarrollo del trópico:elcasode BalancánTenosique, Centro de Ecodesarrollo, México, 1980 .

-Centro de investigaciones de Quintana Roo, Estudio integral de la frontera México-Belice, 4 tomos, CIQROo, Chetumal, 1993.

-Galleti, Hugo, Estatidad, desarrollo de la sociedad civily conservación ecológica. El papel del plan piloto forestal de Quintana Roo, documento inédito, 1994.

-López Mateos, Adolfo, Construyendo el sudeste: Quintana Roo y Yucatán: Oaxaca y Veracruz en la cuenca del Papaloapan, La Justicia, México, 1960.

-Macías Zapata, Gabriel, "Transformaciones histórico-regionales de la frontera México-Belice", en La formación histortca de la frontera sur, CIESAS, México, 1985 (Cuadernos de la Casa Chata, 124).

-Székely, Miguel e Iván Restrepo, Frontera agrícola y colonización, Centro de Ecodesarrollo, México, 1988.

-Tudela, Fernando (comp.), La modernización forzada del trópico. El caso Tabasco. Proyecto Integrado del Golfo, El Colegio de México, México, 1988.

37 Galleti, Estatidad, 1994, p.3. 


\section{HEMEROGRAFÍA}

:Un millón de hectáreas para colonos", Excélsior, 5 de mayo de 1960, México.

" El agrario pide 500 millones al Banco Interamericano de Desarrollo para acomodar a 24000 familias del sudeste", $E x$ célsior, 30 de enero de 1964.

"Programa de dos años, con inversión de 7000 millones. Otros 50000 campesinos, al sudeste", Excélsior, 15 de enero de 1975, México.

-"Que ahora sí se instalará el molino de arroz ejidal", Novedades de Quintana Roo, 23 de mayo de 1976. Chetumal, Q. Roo.

"Critica Gómez Barrera (candidato a diputado federal) el programa de colonización del gobierno federal", Novedades de Quintana Roo, 24 de junio de 1976, Chetumal, Q. Roo.

-"Malos desmontes están erosionando la zona fértil de Álvaro Obregón y Pucté", Novedades de Quintana Roo, 4 de noviembre de 1976, Chetumal, Q. Roo.

- "La falta de coordinación, retardataria de los nuevos centros de población ejidal en el estado", Novedades de Quintana Roo, 8 de noviembre de 1976, Chetumal, Q. Roo.

"Que la falta de seriedad del Banco Rural motiva el retraso en la siembra de arroz", Novedades de Quintana Roo, 12 de febrero de 1977, Chetumal, Q. Roo.

"La excesiva humedad del suelo impide iniciar la siembra de arroz en la ribera del río Hondo", Novedades de Quintana Roo, 16 de marzo de 1977, Chetumal, Q. Roo.

"El arroz cederá el paso a la diversificación de cultivos", Novedades de Quintana Roo, 26 de agosto de 1977, Chetumal, Q. Roo.

-"Pedirá el gobierno la siembra de 3,000 has de caña en Butrón y Madrazo", Novedades de Quintana Roo, 9 de noviembre de 1977, Chetumal, Q. Roo.

-"La Comisión Nacional de la Industria Azucarera (CENIA) se compromete a comprar toda la caña que se produzca en $\mathrm{Bu}$ trón y Madrazo", Novedades de Quintana Roo, 12 de noviembre de 1977, Chetumal, Q. Roo.

-"Ejidatarios de Morocoy marchan para exigir cumplimiento de unas promesas", Novedades de Quintana Roo, 22 de agosto de 1979, Chetumal, Q. Roo.

\section{ARCHIVOS}

-Archivo General de la Nación, ramo Presidentes, exp. Programa de inversiones para la colonización del territorio de Quintana Roo, 8 de noviembre de 1961 .

-Archivo de la Secretaría de la Reforma Agraria, NCPE Guadalajara, exp. Resolución de dotación", 17 de julio de 1972; ejido Sacxán, exp. Derechos agrarios, 23 de julio de 1974, y exp. Dotación, 5 de diciembre de 1976. 